\title{
Application of Alloy 718 in GE Aircraft Engines: Past, Present and Next Five Years
}

\author{
Robert E. Schafrik, Douglas D. Ward, Jon R. Groh \\ GE Aircraft Engines \\ Materials and Process Engineering Department \\ Cincinnati, Ohio 45215
}

\begin{abstract}
GE Aircraft Engine's interest in Alloy 718 dates to the early 1960's. New jet engines were under development for the Supersonic Transport (SST) and the Air Force's C-5A, the first of the wide-body airplanes. These new engines required a stronger, more temperature-capable alloy than A286, without the fabrication limitations of René 41. Alloy 718 subsequently became the most widely used superalloy for aerospace applications. It is the alloy most used at GE Aircraft Engines (GEAE) with application in critical rotating parts, airfoils, supporting structures and pressure vessels.
\end{abstract}

Alloy 718 has both business and technical characteristics that have enabled continued growth of its application base:

- Free license to manufacture has allowed a large material supplier and fabricator base to evolve

- Favorable precipitation kinetics provides substantial processing advantage, particularly weldability and castability.

- Relative manufacturing ease has permitted multiple manufacturing processes and product forms to develop over the years.

Improvements in Alloy 718's quality and cost have fostered continued application in GEAE designs. GEAE has tailored its requirements for melting, conversion, forging, and heat treat processing for high strength Alloy 718 applications, while balancing creep and crack growth behavior. For critical rotor applications, GEAE and its specialty metals supply chain have developed high strength (HS718) and directed aged (DA718 ${ }^{1}$ ) versions of Alloy 718. These variants incorporate process refinements that include cleaner input stock and finer grain processing. These improvements, along with the development of more stringent ultrasonic inspection techniques, have enabled increased Alloy 718 application in demanding GEAE rotor hardware without sacrificing durability or performance.

Investment cast 718 has been extensively utilized in GEAE structural designs to reduce the cost of fabricated components. Its slow precipitation kinetics offers a weldability advantage (important for reduction in manufacturing losses and field repair of hardware), but also enables alternative process methods, such as spray forming, roll forming, and laser deposition. The attractive physical metallurgy and large usage base of Alloy 718 make it the logical first choice for the scale-up of new, low cost manufacturing methods.

Superalloys 718.625 .706 and Various Derivatives

Edited by E.A. loria

TMS (The Minerals Metals \& Materials Society). 2001 
For the future, engine design engineers are demanding an affordable Alloy 718 derivative possessing higher temperature capability. Current applications of Alloy 718 are limited by the metastability of the $\gamma^{\prime \prime}$-strengthening system. Efforts to date, with traditional approaches, to increase the temperature stability of Alloy 718 have not been successful. GEAE advocates the use of computer-based analysis tools to aid the development of a derivative alloy. Success hinges on a well-coordinated effort with government, university, and industry participants to develop the physical and data-driven models and analysis techniques necessary to realize this objective of a higher temperature Alloy 718 derivative within the decade.

\section{Early Alloy 718 Introduction to GE Aircraft Engines (GEAE)}

Before the advent of Alloy 718, turbine manufacturers primarily relied upon precipitationstrengthened stainless steels (i.e., A286) and $\gamma^{\prime}$-strengthened Ni-base superalloy, such as René 41, for elevated temperature applications. However, by the late 1950's, GEAE had bumped up against the mechanical and temperature constraints of the stainless steels. The fabrication difficulties of René41 were well known, such as its susceptibility to strain-age cracking during post-weld heat treatment that required costly special processing to resolve.

In 1960, Huntington Alloys-INCO's Herb Eiselstein promoted Alloy 718 for turbine applications. $^{2}$ The prospect of an alloy with significantly improved ease of manufacture combined with mechanical properties that approach René 41 levels was recognized early by GEAE as a revolutionary change for GEAE designs. Interest from several GEAE engine programs supported evaluation of alloy behavior relative to the existing materials.

For Alloy 718, as-quenched hardness of HRc 20 and lower, from solution could easily be achieved -- a real benefit to formability in fabrication of structures as well as to hot forge of critical rotating structures. The classic slow age-overage precipitation hardening behavior of the $\gamma-\gamma^{\prime \prime}$ strengthening system was credited with causing the weldability improvement and gave insight to the René 41 strain-age cracking phenomenon. As precipitation strengthening is relatively slow, constraint at the weld interface is minimized, so that stresses never rise high enough to initiate cracking. Through-thickness hardening of Alloy 718 to the low HRc 40 s could readily be achieved via subsequent aging using an economically viable heat treating cycle. Sensitivity to notch failure in rupture tests with the standard age was corrected via evolutionary improvements in melt processing and sulfur control.

Due to its excellent balance of properties and reasonable cost, Alloy 718 quickly found adherents within GEAE. By the early 1960s it was slated for use in the X211 nuclear engine and the GE4 (Supersonic Transport) turbines; however, neither of these engines were released for production. The GE4 program did provide much-needed engine experience and a basic understanding of material behavior and manufacturing methods critical to eventual scale-up to production. ${ }^{3}$ Included in these studies was the influence of pre-exposure to $538^{\circ} \mathrm{C}-704^{\circ} \mathrm{C}\left[1000^{\circ} \mathrm{F}-1300^{\circ} \mathrm{F}\right]$ and 10,000 hours following what has become the typical $982^{\circ} \mathrm{C}\left[1800^{\circ} \mathrm{F}\right]$ solution plus $718^{\circ} \mathrm{C}-621^{\circ} \mathrm{C}\left[1325^{\circ} \mathrm{F}+1150^{\circ} \mathrm{F}\right]$ age heat treat cycles. Retention of mechanical properties was intermediate to $\mathrm{R}^{\prime} 41$ and the less capable Astroloy. 
Alloy 718 did show strength due to over-aging of bet $\gamma^{\prime \prime}$ to form orthorhombic delta, which contributes little in the way of strengthening with the exception of grain boundary pinning during forge and heat treat processes. No evidence of embrittlement or TCP precipitation was encountered. In contrast to the two $\gamma^{\prime}$-strengthened alloys, ductility of 718 actually increased with exposure. Extension of the 718 pre-exposure data from this study was supplemented with microstructures and eventually published in open literature. ${ }^{4}$

Alloy 718 was first introduced into a production application for portions of the J93 (XB-70 bomber engine) turbine frame that were welded to wrought INCO 722 rings. This application provided only limited production volume. The next application led to significant production outlet; the GE1 development core evolved to GE's successful, long running TF39/CF66/LM2500 engine family. Selection of 718 forgings for compressor airfoils, critical rotating hardware, and static structures required a fast-paced, focused effort at GEAE and our supplier base to ensure success in the TF39 engine program, as well as in the CF6-6 and LM2500 derivatives.

Figure 1 depicts alloy usage for a typical CF6 engine. Alloy 718 comprises a striking 34 percent of finished component weight. The usage is distributed over forgings and investment castings.

This dominance of Alloy 718 usage by GEAE has continued to the present day.
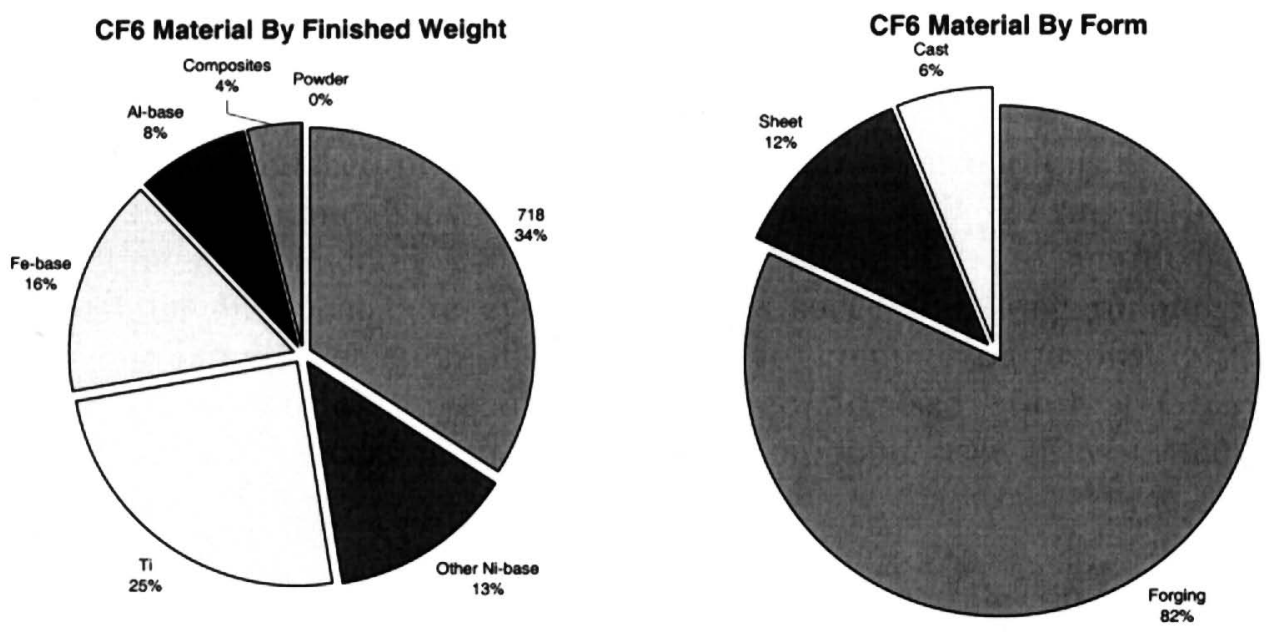

Figure 1. Alloy 718 relative input weights for a typical CF6 configuration. ${ }^{3}$

\section{Current Alloy 718 Applications at GE Aircraft Engines}

All subsequent CF6 derivatives, including the CF6-50/LM5000 and CF6-80C/LM6000 families, incorporated 718 in forged and cast components. Every GEAE engine family applies 718 as the material of choice to applications below approximately $650^{\circ} \mathrm{C}\left[1200^{\circ} \mathrm{F}\right]$. Time at temperature and material condition is considered key to actual maximum operating 
temperature limits. GEAE engine families currently using 718 in production include: F101/F110/CFM56, GE90, T700/CT7, TF34/CF34, F404/F414/LM1600 and CFE738.

Figures 2 and 3 summarize GEAE's current usage of Alloy 718 (not included are purchases by engine partners and sub-tier contractors). Figure 2 indicates usage of Alloy 718 for critical rotating components has remained strong over the last 5 years, even increasing slightly. Figure 3 summarizes the type of material used in GEAE rotating and structural forgings for 2000 . These figures illustrate GEAE's strong commitment to Alloy 718 .
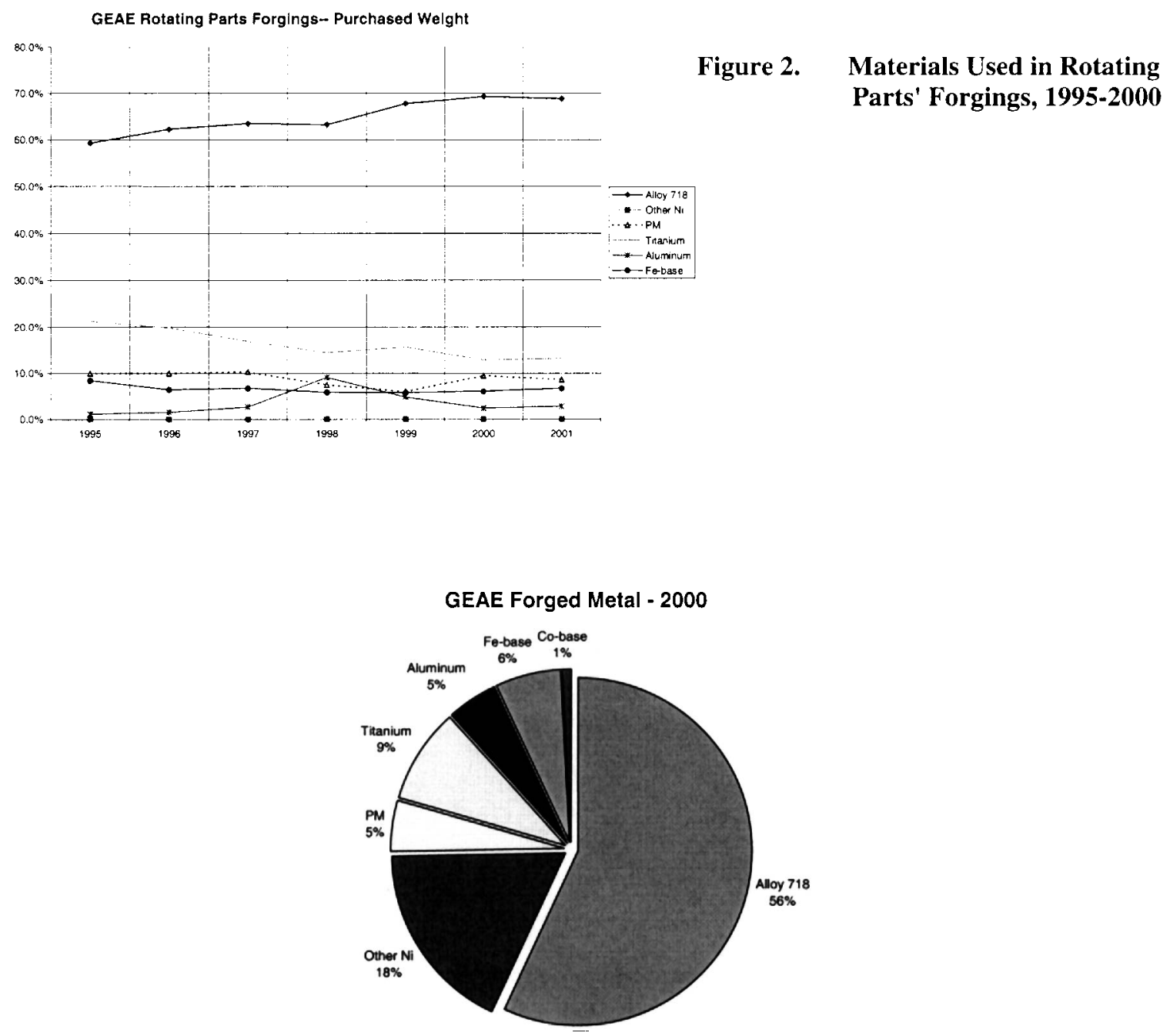

Figure 3. Metals Used in Forgings, CY 2000

Investment cast Alloy 718 has been extensively utilized in GEAE structural designs to reduce manufacturing cycle and cost of traditionally fabricated components. Investment casting has enabled design of components that have incorporated piping, gussets and cooling passages to reduce weight and part count. Large structural castings have also been used to reduce component cost by eliminating welds and associated preps, inspections, 
heat treat and rework cycles. Strength reductions of castings (due to micro-segregation, grain size, and porosity) versus forgings and sheet forms are acceptable for stator components that are often sized by stiffness and casting limitations of wall thickness and radii.

Slow precipitation kinetics make Alloy 718 relatively weldable. This enables the use of large, complex structural castings since fabrication and rework is readily accomplished. An example is shown in Figure 4.

The same weldability advantage provides cost competition due to alternate processing methods. GEAE's structural applications are hot isostatically pressed (HIP'd) only when process yields or properties dictate. Post-HIP or homogenization solution anneal is followed with a final 'Short Age' cycle of $760^{\circ} \mathrm{C}+649^{\circ} \mathrm{C}\left[1400^{\circ} \mathrm{F}+1200^{\circ} \mathrm{F}\right]$; this heat treatment was developed to allow completion within one manufacturing shift.

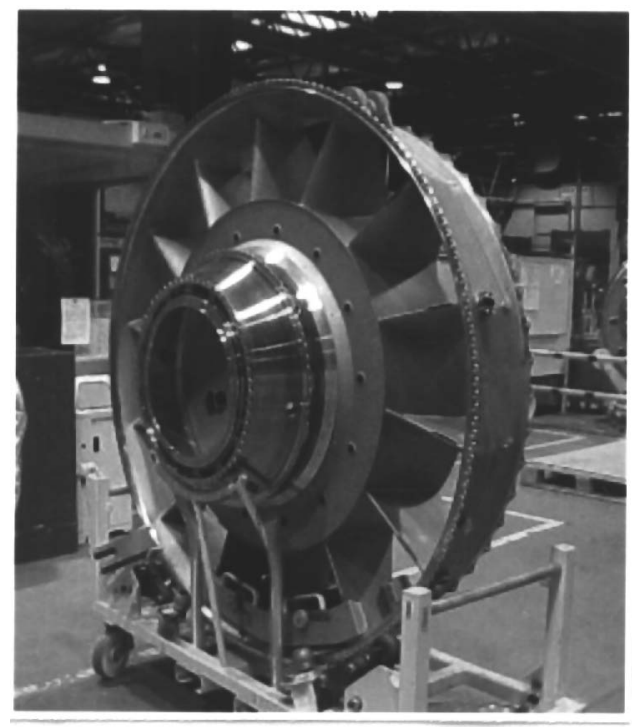

Figure 4. Weldability of Alloy 718 enables application of complex cast structures represented by the GE90 Turbine Rear Frame (matte gray structure with inner and outer annulus connected byintegrally cast struts).

A significant portion of fasteners, locking lugs, blade retainers and inserts are manufactured from Alloy 718 due to the ease with which the material can be processed. Hot head and cold roll characteristics provide affordable, high strength products readily available in standard configurations.

\section{Alloy and Manufacturing Advances}

GE Aircraft Engines and their suppliers have applied detailed knowledge of Alloy 718's physical metallurgy to tailor forge and heat treat schedules for high strength applications while balancing creep and crack growth behavior. The minimum average grain size criterion have been refined from the ASTM 4 of bar stock and premium quality (PQ) forgings to ASTM 8 for High Strength (HS) 718 and ASTM 10 for Direct Age (DA) 718. 
DA718 eliminates the solution cycle, but uses the standard $718^{\circ} \mathrm{C}+621^{\circ} \mathrm{C}\left[1325^{\circ} \mathrm{F}+1150^{\circ} \mathrm{F}\right]$ double age applied following water quench from forge. Retained strain in the as-quenched structure increases $\gamma^{\prime \prime}$ and $\gamma^{\prime}$ precipitation kinetics to increase capability as shown in Table I and Figure 5.

The application of DA718 is a cost effective alternative to powder processing for applications well within 718 temperature limitations. This alloy has a LCF benefit due to grain refinement, but has a debit in creep and crack growth resistance, particularly with a super-imposed hold at maximum load. The accelerated precipitation kinetics of direct age processing also reduces the time-temperature combinations that over-age the alloy.

Table I

Wrought 718 Variants for GEAE Disk Applications

\begin{tabular}{|l|c|c|c|}
\hline $\begin{array}{l}\text { Forged Alloy 718 } \\
\text { Nomenclature }\end{array}$ & $\begin{array}{c}\text { Weight \% } \\
\text { Niobium(Nb) }\end{array}$ & $\begin{array}{c}\text { Minimum Average } \\
\text { Grain Size, } \\
\text { ASTM\# }\end{array}$ & $\begin{array}{c}\text { Nominal RT } \\
\text { UTS (MPa) }\end{array}$ \\
\hline Premium Quality (PQ) & $4.75-5.5$ & 4 & 1380 \\
\hline High Strength (HS) & $5.0-5.5$ & 8 & 1435 \\
\hline Direct Age (DA) & $5.0-5.5$ & 10 & 1470 \\
\hline
\end{tabular}

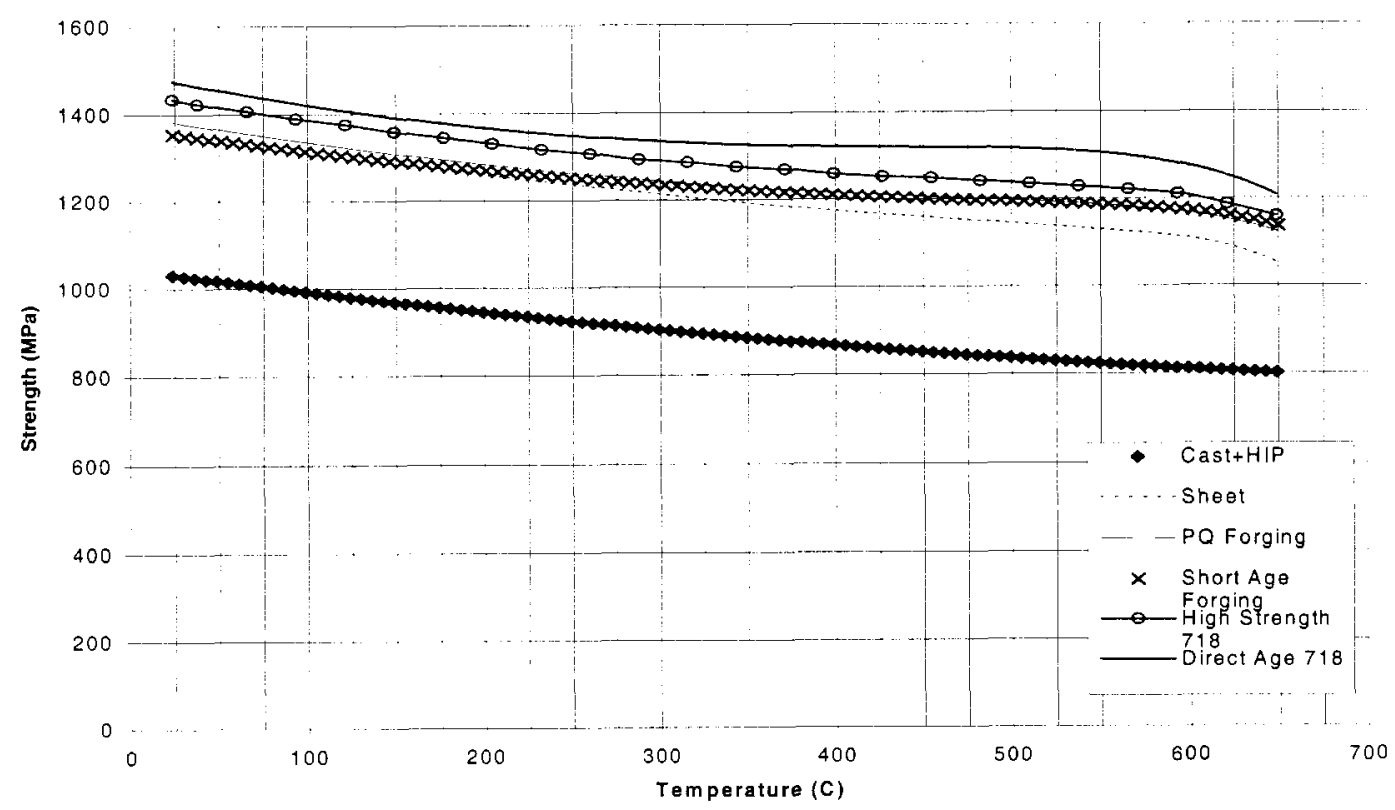

Figure 5. Nominal tensile strength comparison of 718 variants applied to GEAE production. 
GEAE's HS718 and DA718 specifications have driven industry to increase the niobium $(\mathrm{Nb})$ content of Alloy 718 toward the upper limit of 4.75-5.5 weight percent specification range. ${ }^{5}$ Metal producers have switched nearly all production to this composition to ease logistics. Increasing $\mathrm{Nb}$ correlates to an increase in the observed $\delta$-solvus temperature ${ }^{6}$ as shown in Figure 6. For HS and even PQ-718, the solution cycle has required adjustment to prevent precipitation of excess $\delta$-phase in today's forgings, a known detriment to creep resistance. ${ }^{7}$ Similarly, the finish forge temperature of DA718 has been modified to achieve the required property balance, as indicated in Figure 7.

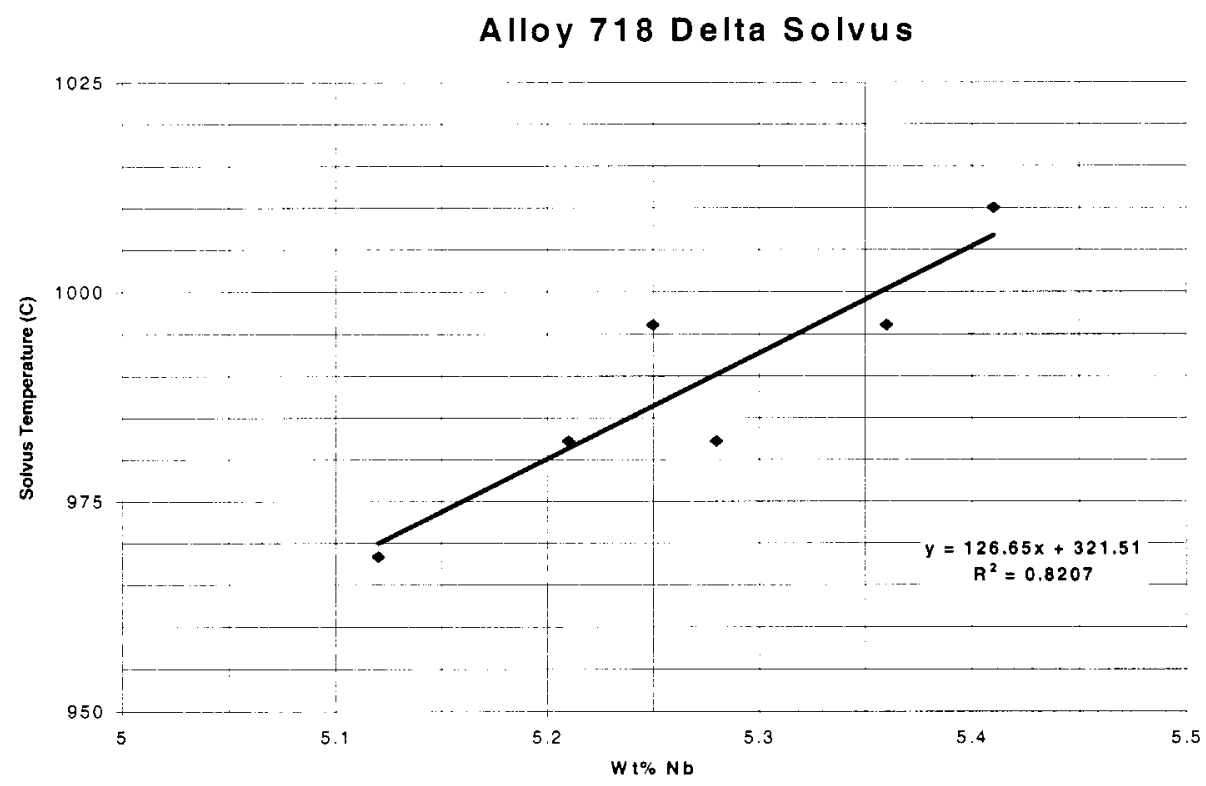

Figure 6. Correlation of niobium content to $\delta$-solvus.

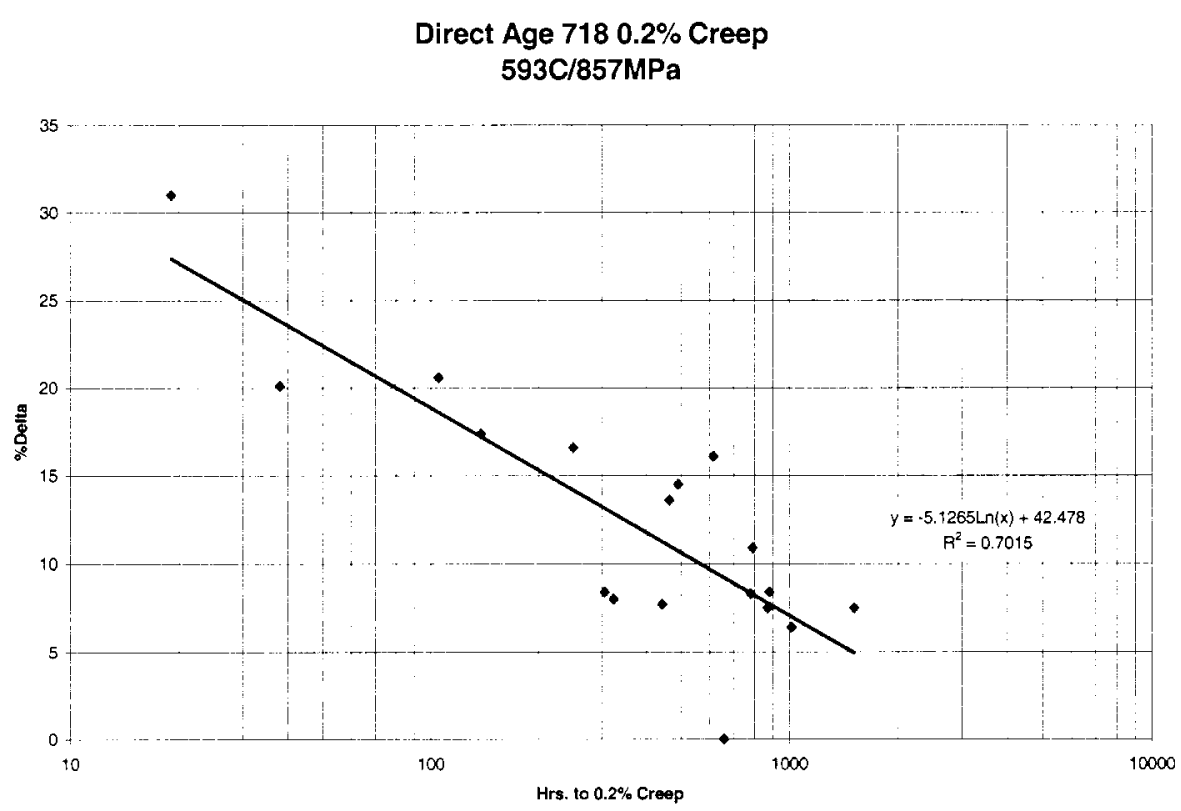

Figure 7. Creep Behavior of DA718 as a Function of Delta Phase Content. Excess delta precipitate debits creep resistance 
Additional tensile and fatigue capability for wrought applications was realized with the introduction of clean melt technologies. Electroslag remelt of VIM stock prior to VAR effectively breaks down the size of non-metallic inclusions and minimizes retention of macrosegregation from VIM solidification. Segregation of $\mathrm{Nb}$ after ESR was encountered as grain size banding due to the variation in delta precipitates forming along forging flow lines. This segregation is eliminated by a final VAR step. More stringent ultrasonic inspection methods were introduced to assure that defects above a certain size are not present.

Critical components manufactured from Alloy 718 are currently processed via the triple melt VIM+ESR+VAR route that typically exhibits no evidence of either white spots or freckling associated with VIM+VAR product. Similar benefits were reported ${ }^{7}$ with respect to the reduced frequency of ultrasonic indications in 718 billet.

Alloy 718 material and cost efficiencies have been improved for critical rotating components with the advent of hot die forging and inertia welding. Relatively near net shape forgings are semi-finish machined with weld preps set to achieve aim finish dimensions. The solid-state inertia weld is achieved using the friction generated at the interface to reach temperature followed by forge upset. As the material is joined sub-solvus, weld structures are extremely fine grained with tensile and low cycle fatigue strengths as high as the parent metal. Figure 8 depicts microstructure of an Alloy 718-to-René 88DT joint. Evident is the relatively low flow stress of the Alloy 718 and the very fine structure achieved at the interface. Tensile and fatigue properties of this joint are typically superior to that of the parent materials. Inertia welds have also been applied to structural cases to provide material for embossments, bolt pads, and other protrusions. This reduces overall part cost by improving buy-to-fly ratio (material input weight vs. finish part weight) as well as minimizing machining required to mill material from between protrusions.
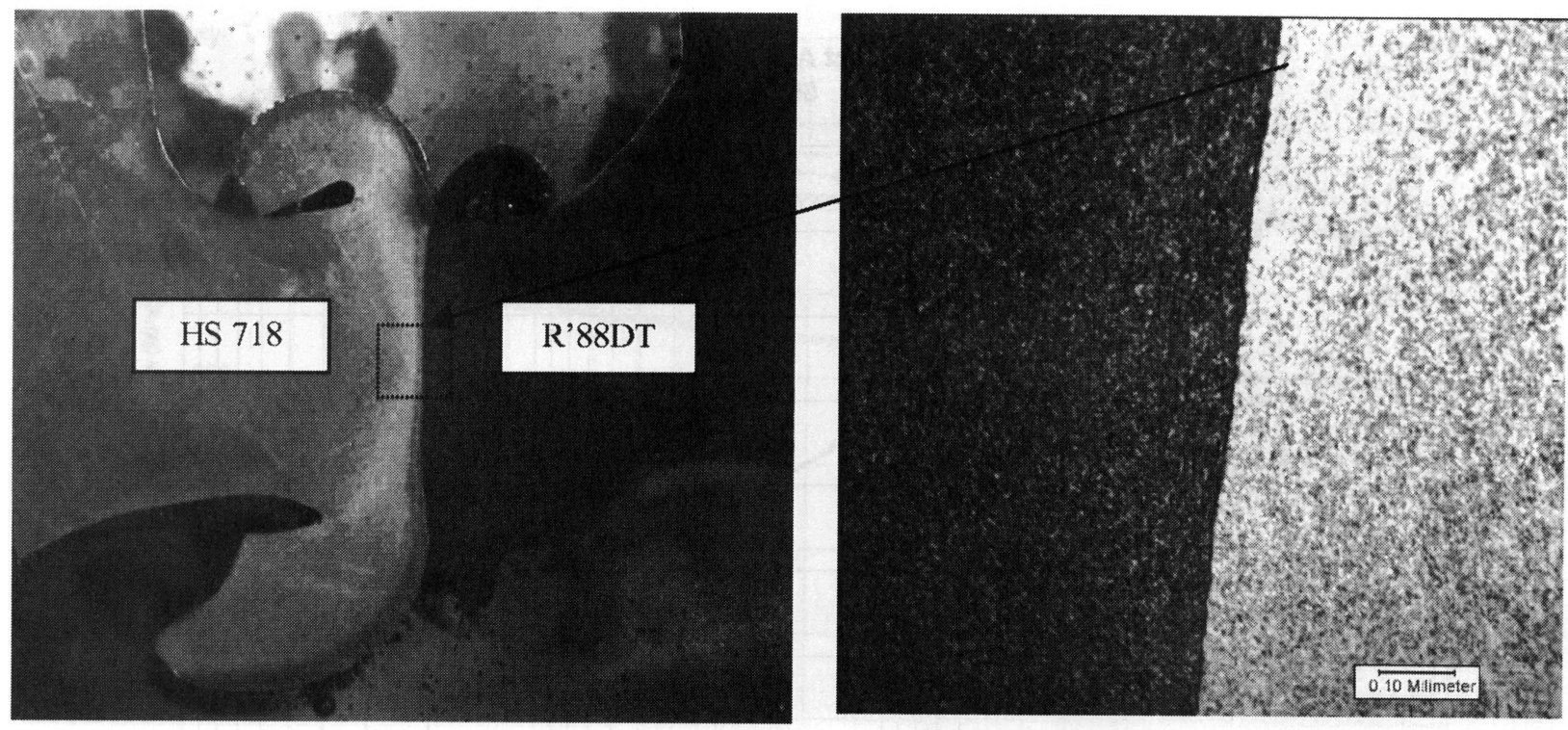

Figure 8. Macro and micrographs showing bialloy inertia weld appearance also illustrate relatively low flow stress of Alloy 718. Grain refinements at the bond line typically benefits tensile and fatigue properties. 
A similar solid-state weld is often applied to ring structures via flash-weld of either rectangular or shaped barstock as an alternate process to seamless ring roll. Coarse grain heat affect zone across the flash weld is typically created by upset after resistance heat of the surfaces to be joined. Mechanical strengths across this joint are comparable to parent-metal Alloy 718 with the exception of ductility.

The excellent malleability and weldability characteristics of the 718 system make the material physical properties relatively tolerant of manufacturing processes. These characteristics additionally continue to provide new opportunities for advanced manufacturing methods to further reduce cost and cycle time. New manufacturing methods in various stages of development include roll and spray form of structural components, spray form as an alternate method of providing embossments, free-form laser build up and friction stir welding.

\section{High Temperature Capability - Modeling Approach}

Additional application of Alloy 718 is hampered by its overage response documented in previous Alloy 718 symposia $^{(4,8,9)}$. Increasing engine temperatures are dictating the selection of alloys with greater temperature capability than Alloy 718. However, migrating from Alloy 718 usually results in undesirable cost and weight penalties, particularly since these other materials can pose significant component manufacturing challenges.

An affordable Alloy 718 derivative with greater temperature capability is a long-standing desire. GEAE has developed and applied $\gamma^{\prime \prime}$-strengthened René 220 in cast form for production applications nominally $39^{\circ} \mathrm{C}\left(100^{\circ} \mathrm{F}\right)$ hotter than 718 which exhibits weldability equivalent to investment cast 718. Marginally weldable $\gamma^{\prime}$-strengthened alloys of the René 41/Waspaloy class suffer a high ratio of input to finished weight and are difficult to machine. To date, efforts to increase the metallurgical stability of 718 have not yielded an affordable derivative or alternative of a $1718+39^{\circ} \mathrm{C}$ " alloy for wrought components for either critical static or rotor applications. However, this type of alloy will require a large user base to realize a cost benefit. A rapid build-up of volume will be critical to establishing the supporting infrastructure for this new alloy (e.g., revert, recycling and production capacity).

GEAE has performed a feasibility study to revisit the potential for an Alloy 718 derivative that would be cost competitive with the Waspaloy/René 41 family and having processing characteristics similar to 718. The wrought version of René 220 was assessed and, while providing technically encouraging results, was eliminated due to high elemental costs. However, replacement of nominally half of the Fe in Alloy 718 with Co plus Ta yielded a temperature capability between 718 and Waspaloy. Elemental costs of this "Alloy 991" ( 9 weight percent $\mathrm{Fe}, 9$ weight percent $\mathrm{Co}, 1$ weight percent $\mathrm{Ta}$ ) are approximately 10 percent greater than Waspaloy. Processing to an intermediate grain size via thermomechanical processing may provide a property balance similar to that of Waspaloy. Its weldability will provide opportunities for repair and use in alternate manufacturing processes. Results of preliminary creep tests are shown in Figure 9. 


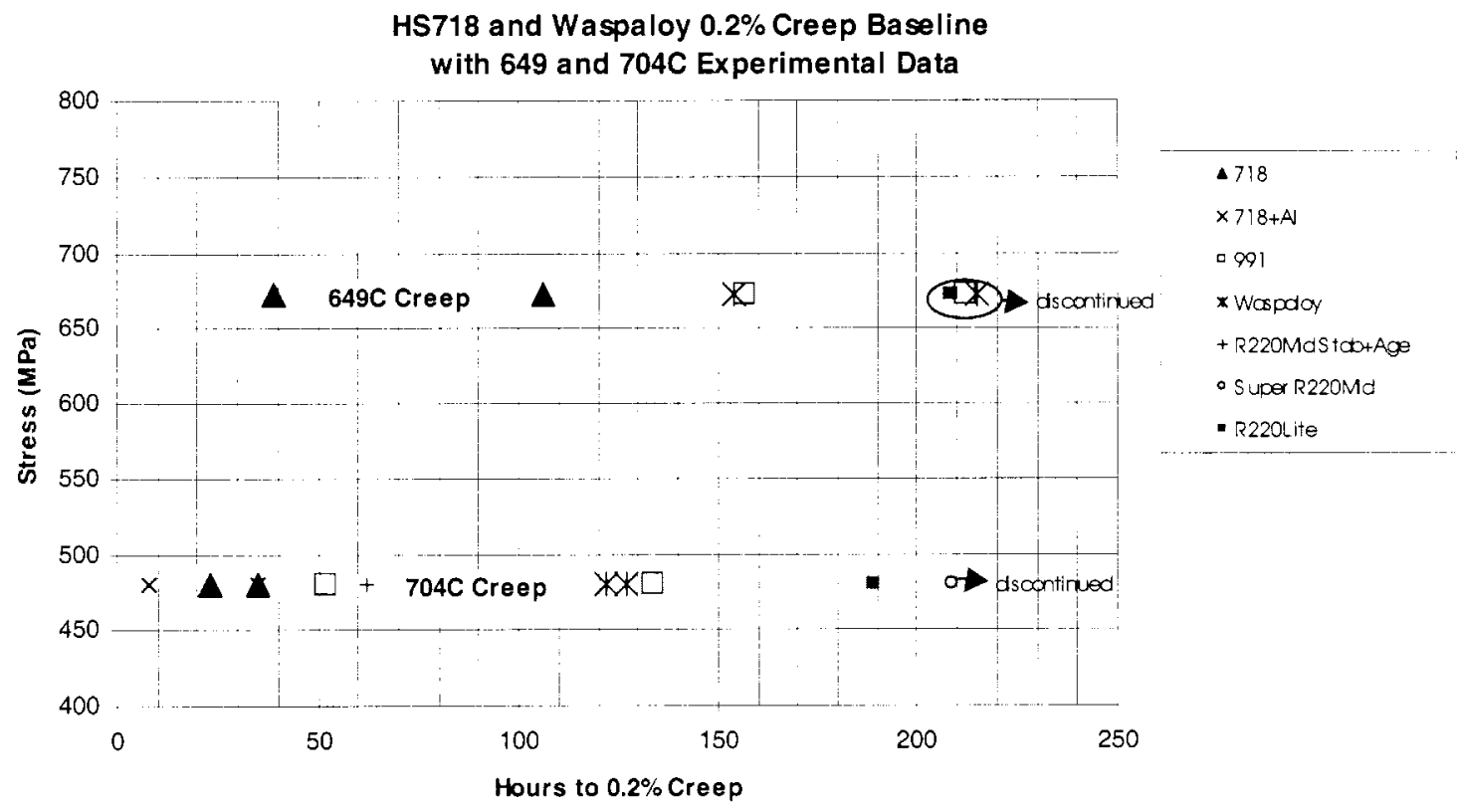

Figure 9. Creep data from GEAE Alloy $718+39^{\circ} \mathrm{C}$ feasibility study showing potential of "Alloy 991"

Recently, GEAE formed a cooperative alliance with Pratt-Whitney, Ladish, Allvac, Carpenter Technology and Honeywell to propose a Metals Affordability Initiative (MAI) program (US Air Force funded) entitled Low Cost, High Temperature Structural Material Development. The new alloy is targeted to have the malleability and fusion weldability characteristics of Alloy 718 , with stability to the same higher temperature range as Waspaloy and René 41 . A well-coordinated effort among melt and forging suppliers and engine manufactures is required to realize this objective in the next 5 years. Key technical and cost requirements for this new alloy are summarized in Table II.

\section{Table II. Key Requirements for a New Low Cost, High Temperature Structural Material}

- Component cost less than $75 \%$ of Waspaloy.

- Comparable metallurgical stability at $704^{\circ} \mathrm{C}\left(1300^{\circ} \mathrm{F}\right)$ as Alloy 718 at $621^{\circ} \mathrm{C}\left(1150^{\circ} \mathrm{F}\right)$.

- Creep resistance and tensile strength at $649^{\circ} \mathrm{C}\left(1200^{\circ} \mathrm{F}\right)$ and $704^{\circ} \mathrm{C}\left(1300^{\circ} \mathrm{F}\right)$ at least equal to Waspaloy.

- Stress rupture properties equal or higher to Waspaloy for selected conditions

- Ductility at processing temperatures equivalent to IN718

- Ductility at running engine part temperatures equivalent to Waspaloy

- Wear resistance and weldability equivalent to IN718 at the selected conditions 
This alloy development effort will incorporate physics and cost-based models to accelerate traditional empirical fabrication and test approach. Initial alloy candidates will be thermodynamically modeled for characteristics including solid/liquid segregation, partitioning coefficients, precipitation kinetics and multi-component phase diagrams. They will be assessed to provide physical based selection criteria for a focused alloy selection. Physical based models are considered a key tool in the acceleration of future alloy development efforts. Contract award is pending with work beginning $2 \mathrm{Q} 01$ and completion in 2004.

\section{Summary}

For GE Aircraft Engines, Inco's development of Alloy 718 was quite significant and important. Alloy 718 is arguably the most successful superalloy to date. It has been the alloy of choice for affordable components in GEAE's aero engines and land-base derivatives for more than 35 years. Alloy 718 possesses an appropriate combination of strength and ductility to about $650^{\circ} \mathrm{C}$, precipitate stability, weldability, castability and ease of machining.

As we look to the future, the versatility of Alloy 718 ensures its continued usage, albeit for a smaller portion of future engine components due to increasing engine operating temperatures. Finding a suitable higher temperature counterpart to Alloy 718 has proven to be a daunting task. GEAE advocates cooperation amongst industry, government and university partners to develop this next generation alloy. While success is not guaranteed, it is an effort worth taking. It will be interesting to look back in another 35 years to see how successful we have been with this new alloy - to be sure, Alloy 718 set the bar quite high.

\section{References}

1 D.D. Krueger, "The Development of Direct Age 718 for Gas Turbine Engine Disk Applications", Superalloy 718 Metallurgy and Applications, TMS, 1989, p.279-296.

2 E.L. Raymond, personal conversations, 2000.

3 J.F. Barker, "The Initial Years of Alloy 718 - A GE Perspective", Superalloy 718 Metallurgy andApplications, TMS, 1989, p.269-277.

4 J.F. Barker, E.W. Ross, and J.F. Radavich, "Long Time Stability of In718", Journal of Metals,January 1970.

5 AMS 5663, "Nickel Alloy, Corrosion and Heat Resistant, Bars, Forgings, and Rings"

6 J.R. Groh, "The Effects of Process Variations and 0.2\% Creep Life of Direct Age Alloy 718", GE TM 85-336, 8/2/85.

7 J.M. Moyer, L.A. Jackman, C.B. Adasczik, R.M. Davis, and R. Forbes-Jones, "Advances in Triple Melting Superalloys 718, 706, and 720", Superalloys 718, 625, 706, and Various Derivatives, TMS 1994, p.39-48

8 G.E. Korth and C.L. Trybus, "Tensile Properties and Microstructure of Alloy 718 Thermally Aged to 50,000 h", Superalloys 718, 625, and Various Derivatives, TMS 1991, p.437-446.

9 A.Oradei-Basile and J.F. Radavich, "A Current T-T-T Diagram for Wrought Alloy 718", Superalloys 718, 625, and Various Derivatives, TMS 1991, p.325-335.

\section{Acknowledgements}

The authors would like to gratefully acknowledge Terry Dyer, Gary Berling and Steve Bierman for their support and contribution to this paper. 